\title{
Age and education as factors associated with medication literacy: a community pharmacy perspective
}

\author{
Javier Plaza-Zamora ${ }^{1 \dagger}$, Isabel Legaz ${ }^{2 *} \mathbb{D}$, Eduardo Osuna ${ }^{2}$ and María D. Pérez-Cárceles ${ }^{2}$
}

\begin{abstract}
Background: Aging implies a higher prevalence of chronic pathologies and a corresponding increase in medication. The correct adherence and use of the medication are prerequisites for reducing risks of disease progression, comorbidity, and mortality. Medication literacy (ML) is the specific ability to safely access and understand the information available concerning medication, and to act accordingly. Currently, there are few specific instruments that ascertain the extent of ML in the general population. The aim of this work was to analyse ML in a large cohort of pharmacy customers.

Methods: A total of 400 community pharmacy clients were analyzed to assess the level of ML (documental and numeracy) through the validated MedLitRxSE tool.

Results: The results showed that out of a total of 400 community pharmacy clients only 136 (34\%) had an adequate degree of ML, while the rest of the clients $(n=264 ; 66 \%)$ were adjudged not to have this ability. Statistically significant differences were found between the different age groups in terms of $\mathrm{ML}(P<0.001$; $\mathrm{OR}=0.312 ; 95 \% \mathrm{Cl}: 0.195-0.499)$, the 51-65 and $>65$-year age groups having a lower frequency of adequate ML (23.5 and 7.1\%, respectively) than the rest of the age groups. A statistically significant increase in adequate ML was observed as the academic level of the clients increased $(P<0.001$; $\mathrm{OR}=15.403 ; 95 \% \mathrm{Cl}:$ 8.109-29.257). Multivariate logistic regression confirmed the influence of both variables on ML.

Conclusions: An inadequate ML level was found in community pharmacy clients over the age of 51, and also in those with primary or non-formal studies. Our data add to our knowledge about ML, and should pharmacists and other health professionals to adopt new strategies to prevent, or at least reduce, errors in taking medicines, thus avoiding the undesirable effects of any misuse.
\end{abstract}

Keywords: Aging, Community pharmacy, Education, Legal medicine, Patient safety

\footnotetext{
*Correspondence: isalegaz@um.es

${ }^{\dagger}$ Javier Plaza-Zamora and Isabel Legaz contributed equally to this work.

${ }^{2}$ Department of Legal and Forensic Medicine, Institute of Research into Aging. Biomedical Research Institute (IMIB), Regional Campus of International Excellence "Campus Mare Nostrum", Faculty of Medicine, University of Murcia, Murcia, Spain

Full list of author information is available at the end of the article
}

(C) The Author(s). 2020 Open Access This article is licensed under a Creative Commons Attribution 4.0 International License, which permits use, sharing, adaptation, distribution and reproduction in any medium or format, as long as you give appropriate credit to the original author(s) and the source, provide a link to the Creative Commons licence, and indicate if changes were made. The images or other third party material in this article are included in the article's Creative Commons licence, unless indicated otherwise in a credit line to the material. If material is not included in the article's Creative Commons licence and your intended use is not permitted by statutory regulation or exceeds the permitted use, you will need to obtain permission directly from the copyright holder. To view a copy of this licence, visit http://creativecommons.org/licenses/by/4.0/ The Creative Commons Public Domain Dedication waiver (http://creativecommons.org/publicdomain/zero/1.0/) applies to the data made available in this article, unless otherwise stated in a credit line to the data. 


\section{Background}

Aging implies a higher prevalence of chronic pathologies and therefore an increase in medication $[1,2]$. However, the correct use of the medication is a prerequisite for reducing the risks of disease progression, comorbidity, and mortality $[3,4]$.

Older patients are major users of both prescription and non-prescription medicines, and their proper use will lead to more cost-effective approaches and increase safety [57]. Medication non-adherence, or the extent to which patients do not take their medications as agreed with their health care provider, averages 50\% among patients suffering from chronic diseases in developed countries [5] and results in poorer health outcomes and a lower quality of life in patients [8]. Inadequate prescription details or misunderstanding instructions is often associated with limited information and a poor knowledge of medication use, leading to errors and less effective treatment [9, 10]. Moreover, most adverse drug reactions are related to excessive dosage and drug interactions associated with polypharmacy $[11,12]$.

Medication literacy (ML) is the specific ability to safely access and understand the information available concerning medication, and act accordingly [13]. Although there are some instruments available for its evaluation [13], ML is not fully recognized. Only about $50 \%$ of patients [11] follow chronic medication instructions, a figure that could be improved by encouraging the participation of patients in their treatments. In order to achieve the maximum effect and a safety in the use of medication, patients and caregivers must have adequate knowledge of the therapy. Perhaps more seriously, the safety of children is at risk due to parents' lack of knowledge about medication administration $[9,14,15]$.

A proper use of the medication includes how to administer it, when, for how long, what quantity [16]. This information must be provided first by the health professionals in a simple and effective way adapted to the particular patient but also by medication information sheets that are readable with pictograms to help patient comprehension and avoid the misuse of the medicines [17, 18]. For their part, pharmacists want their patients to take their medication and to follow treatment strategy properly. To meet these standards, it is critical that patients not only have sufficient information, but also sufficient reading, coding, and self-management skills to use that information $[19,20]$.

ML includes skills such as interpretation and the ability to calculate doses, and cannot be measured properly by general evaluations of literacy. However, it is important to be able to assess numerical and/or documental knowledge before receiving written or verbal instructions from health professionals about preparing medication doses, the duration of treatment and any warnings [21].
Community pharmacists could evaluate ML prior to carrying out a medication review [22], so they can know what areas need reinforcing to improve the proper understanding by the patient, thus influencing their ability to adhere to the treatment. Despite the absence of tools to measure medical literacy, there is a need on the part of community pharmacists to quickly and specifically assess the ML of their patients.

In this study the ML of clients acquiring prescription and non-prescription medicines in community pharmacies was analyzed using MedlitRxSE questionnaire in order to the future purpose of designing new strategies that allow the pharmacist and health personnel to prevent and reduce the errors in taking medicines and thus avoid the undesirable effects of any misuse.

\section{Methods}

\section{Participants}

The sample size initially calculated was to represent a population of 2500 people, since in Spain this is the average number of inhabitants per pharmacy office, with an accuracy of $5 \%(\mathrm{e}=0.05)$ and with a $95 \%$ confidence interval. The calculated sample size was 334 subjects, to which we added $20 \%$ to cover possible withdrawals. The final sample consisted of 400 community pharmacy clients.

All 400 clients answered the validated MedLitRxSE tool [13] anonymously. The pharmacy staff from each pharmacy office participating provided information about the study when they went to the pharmacy office. The data for this study were collected at the pharmacy office. The clients comprised caregivers or clients who simply came to pick up collect medication for their relatives or for themselves.

Four community pharmacies were randomly selected from 20 offices in an area in south-eastern Spain. They were located in rural and urban areas. Rural areas were defined as areas with a low population density $(<2500$ habitants) and urban areas were those with a high population density (>2500 inhabitants) [23]. Each pharmacy conducted 100 surveys, which included sociodemographic data, the consumption of medication and the frequency with which the patient read the information leaflet. The study was carried out between January 2016 and December 2018.

The inclusion criteria considered were clients over 18 years of age, users of public or private health services who went to the community pharmacy and asked for a medicine prescribed by a doctor or an over-the-counter medicine for personal use or for someone else.

All participants were informed of the study through the pharmaceutical staff attached to the community pharmacy, obtaining written informed consent in all cases. The study and protocols for recruitment were 
approved by the Human Research Ethics Committee of the University of Murcia (Approval number: 1896/2018, date of approval 10 April 2018) in accordance with the 'Ethical Principles for Medical Research Involving $\mathrm{Hu}-$ man Subjects' adopted in the Helsinki Declaration by the World Medical Association (64thth WMA General Assembly, Fortaleza, Brazil, October 2013).

\section{Medication literacy assessment}

To use the MedLitRxSEs (Medication Literacy Assessment) tool, the authors were previously contacted, and they provided us with all the necessary information. A psychometric evaluation of this new assessment tool is described by authors who designed the instrument, and the Spanish version has been shown satisfactory in this respect (13). The MedLitRxSE is a tool that assesses the skills needed to manage medication properly. It consists of 14 items organized in four scenarios, of which 10 items relate to document literacy and 4 to numeracy, all with a dichotomous response (Table S1). A possible range of $0-14$ points can be obtained, in such a way that a higher score reflects greater literacy with medication. The MedLitRxSE does not have scoring criteria from which medication literacy levels can be obtained, but identifying the most commonly missed questions can give pharmacists clues as to the deficiencies of patients in understanding prescription information and dosage instructions. Any error suggests potential confusion or concern about the safety or use of the medication. Thus, pharmacists who provide medication or disease therapy management services may consider including this questionnaire on the first occasion a patient visits the pharmacy as a way of assessing any areas of possible misunderstanding related to the use of medications [13].

In order to understand the factors associated with ML, this qualitative variable (documental and numeracy) was converted into 2 dichotomies: inadequate and adequate ML, and a cut-off point was established to categorize ML. MedLiTRxSE does not establish a cut-off point to differentiate between adequate and inadequate medication literacy. As experts in the field we established that of the 14 possible points in MedLiTRxSE tool with 13 points we should consider an adequate ML. To achieve a higher range (adequate literacy) we assumed that of the 14 competencies evaluated by the tool, only one could fail: knowing the name of the doctor who had prescribed the drug or knowing the name of the active ingredients, both competencies from documentary medication literacy. In the case of numeracy medication literacy, we consider that when trying to know and use the doses of the drugs in an appropriate way, the requirement to consider it as adequate was greater, establishing the four questions as correct. Therefore, an adequate literacy score was established to be $\geq 13$ points for total ML, $\geq 9$ points for document ML, and 4 points for numeracy-ML.

Univariate and multivariate analyses with logistic regression of all the variables pointed to a significant relation with the dependent variable in the bivariate analyses [24]. Then, by backward stepwise selection, a model was obtained with the individual variables directly related to the dependent variable, adequate ML.

\section{Statistical analysis}

Sociodemographic data and the results of each survey were collected in a database (Microsoft Access 11.0; Microsoft corporation, Seattle, WA), and statistical analysis was performed using the SPSS 15.0 software (SPSS Inc., Chicago IL, USA). Categorical data were compared using chi-square $\left(\mathrm{X}^{2}\right)$ test or Fisher's Exact test, and non-parametric count data were compared using the Kruskal Wallis test or Mann Whitney U test. Inadequate and adequate ML were compared using bivariate analyses to determine whether there was any difference in the descriptive characteristics (age, sex, education). Logistic regression univariate and multivariate analysis was used to examine factors associated with adequate medication literacy. A level of $P<0.05$ was accepted as statistically significant. The odds ratios (OR) and their 95\% confidence intervals $(\mathrm{CI})$ were calculated in order to estimate relative risk. The I-square (I2) statistic with cut-off values of $73.1 \%$ and a $p$-value of $<0.001$ was considered statistically significant.

\section{Results}

\section{Demographic characteristics}

A total of 400 community pharmacy clients, including 136 males (34\%) and 264 females (66\%) were analyzed in this study (Table 1). The median age of the total cohort was $49.65 \pm 16.62$ (years \pm SD). The four age groups analyzed were equally represented and no significant differences were found $\left(X^{2}=0.090\right)$. Individuals under 50 years represented $53.5 \%$ of the total while individuals over or equal to 51 years represented $46.5 \%$.

Analysis of the different education levels pointed to statistically significant $\left(\mathrm{X}^{2}=0.003\right)$ differences: $42.5 \%$ had received only primary education or no official education, and $57.5 \%$ had secondary or university levels of education (32.3 and $25.2 \%$, respectively).

As regards the pharmacies where the clients' replies were analyzed, $41 \%$ were rural community pharmacies, while $59 \%$ were in urban areas. Finally, as regards the reading of medicine leaflets, $24.8 \%$ said they never read the information provided, $28.2 \%$ sometimes and $47.0 \%$ always. There was no significant association between adequate and inadequate literacy and leaflet reading frequency $(P=0.180)$. However, an increase in the frequency of reading the leaflets did lead to a 
Table 1 Analysis of the sociodemographic characteristics, pharmacies areas, number of medications consumed and reading information leaflet of community pharmacy clients and its relationship with medicacion literacy. (a) Analysis of adequate or inadequate medication literacy (b) Analysis of correct answers in MedLiTRxSE tool

\begin{tabular}{|c|c|c|c|c|c|c|c|c|c|c|}
\hline & \multirow{2}{*}{$\begin{array}{l}\text { Total } \\
N=400 \\
\mathrm{n}(\%)\end{array}$} & \multicolumn{2}{|c|}{ (a) Medication Literacy } & \multirow[t]{2}{*}{ P1 } & \multicolumn{4}{|c|}{ (b) Medication Literacy } & \multirow[t]{2}{*}{ P3 } & \multirow[t]{2}{*}{ P4 } \\
\hline & & $\begin{array}{l}\text { Adequate } \\
N=136 \\
\text { n (\%) }\end{array}$ & $\begin{array}{l}\text { Inadequate } \\
N=264 \\
\mathrm{n}(\%)\end{array}$ & & Total & P2 & Documental & Numerical & & \\
\hline \multicolumn{11}{|l|}{ Gender } \\
\hline Male & $136(34.0)$ & $57(41.9)$ & 79 (58.1) & $0.019^{\mathrm{a}}$ & $10.72 \pm 3.52^{*}$ & 0.075 & $7.42 \pm 2.59$ & $3.31 \pm 1.08$ & 0.008 & 0.268 \\
\hline Female & $264(66.0)$ & 79 (29.9) & $185(70.1)$ & & $10.08 \pm 3.34$ & & $6.88 \pm 2.46$ & $3.23 \pm 1.09$ & & \\
\hline \multicolumn{11}{|l|}{ Age intervals, years } \\
\hline$<35$ & $99(24.8)$ & $54(54.5)$ & $45(45.5)$ & & $12.28 \pm 1.58$ & & $8.52 \pm 1.30$ & $3.77 \pm 0.51$ & & \\
\hline $35-50$ & $115(28.7)$ & $52(45.2)$ & $63(54.8)$ & $<0.001^{b}$ & $11.50 \pm 2.33$ & $<0.001$ & $7.89 \pm 1.87$ & $3.61 \pm 0.66$ & $<0.001$ & $<0.001$ \\
\hline $51-65$ & $102(25.5)$ & $24(23.5)$ & $78(76.5)$ & & $10.00 \pm 3.09$ & & $6.81 \pm 2.31$ & $3.19 \pm 0.99$ & & \\
\hline$>65$ & $84(21.0)$ & $6(7.1)$ & $78(92.9)$ & & $6.68 \pm 3.73$ & & $4.54 \pm 2.66$ & $2.14 \pm 1.35$ & & \\
\hline \multicolumn{11}{|l|}{ Education level } \\
\hline $\begin{array}{l}\text { Primary or no formal studies or } \\
\text { any study }\end{array}$ & $170(42.5)$ & $12(7.1)$ & $158(92.9)$ & & $4.77 \pm 3.42$ & & $2.91 \pm 2.45$ & $1.86 \pm 1.17$ & & \\
\hline Secondary & $129(32.3)$ & $57(44.2)$ & $72(55.8)$ & $<0.001^{c}$ & $11.80 \pm 1.81$ & $<0.001$ & $8.10 \pm 1.56$ & $3.70 \pm 0.54$ & $<0.001$ & $<0.001$ \\
\hline University & $101(25.2)$ & $67(66.3)$ & $34(33.7)$ & & $12.67 \pm 1.46$ & & $8.79 \pm 1.28$ & $3.88 \pm 0.35$ & & \\
\hline \multicolumn{11}{|l|}{ Pharmacies areas } \\
\hline Rural & $164(41.0)$ & $64(39.0)$ & $100(61.0)$ & 0.086 & $10.65 \pm 3.36$ & 0.083 & $7.32 \pm 2.45$ & $3.33 \pm 1.10$ & 0.069 & 0.154 \\
\hline Urban & $236(59.0)$ & $72(30.5)$ & $164(69.5)$ & & $10.05 \pm 3.43$ & & $6.89 \pm 2.54$ & $3.17 \pm 1.08$ & & \\
\hline \multicolumn{11}{|l|}{ Number of medications consumed } \\
\hline No medicines & $151(37.8)$ & $74(49.0)$ & $77(51.0)$ & $<0.001^{d}$ & $11.81 \pm 2.17$ & $<0.001$ & $8.15 \pm 1.67$ & $3.67 \pm 0.68$ & $<0.001$ & $<0.001$ \\
\hline $1-4$ medicines & $179(44.7)$ & $57(31.8)$ & $122(68.2)$ & & $10.31 \pm 3.21$ & & $7.06 \pm 2.44$ & $3.26 \pm 0.99$ & & \\
\hline$\geq 5$ medicines & $70(17.5)$ & $5(7.1)$ & $65(92.9)$ & & $6.99 \pm 3.78$ & & $4.75 \pm 2.67$ & $2.23 \pm 1.36$ & & \\
\hline \multicolumn{11}{|l|}{ Consumption of chronic medication } \\
\hline Yes & $249(44.8)$ & $62(24.9)$ & $187(75.1)$ & $<0.001^{\mathrm{e}}$ & $6.08 \pm 3.16$ & $<0.001$ & $6.03 \pm 2.18$ & $2.86 \pm 1.34$ & 0.002 & 0.002 \\
\hline Non & $151(37.7)$ & $74(49.0)$ & $77(51.0)$ & & $10.91 \pm 2.84$ & & $7.56 \pm 2.05$ & $3.36 \pm 1.01$ & & \\
\hline \multicolumn{11}{|l|}{ Reading information leaflet } \\
\hline Never & $99(24.8)$ & $28(28.3)$ & $71(71.7)$ & & $8.94 \pm 4.32$ & & $6.08 \pm 3.16$ & $2.86 \pm 1.34$ & & \\
\hline Sometimes & $113(28.2)$ & $40(35.4)$ & $73(64.6)$ & 0.180 & $10.47 \pm 3.05$ & 0.004 & $7.11 \pm 2.34$ & $3.35 \pm 0.88$ & 0.002 & 0.002 \\
\hline Always & $188(47.0)$ & $68(36.2)$ & $120(63.8)$ & & $10.91 \pm 2.84$ & & $7.58 \pm 2.37$ & $3.36 \pm 1.01$ & & \\
\hline
\end{tabular}

$N$ total number of individuals, $n$ number of individuals in each study, $S D$ standard deviation. P1. Comparisons adequate and inadequate were made by the two-sided Fisher's exact test or Pearson's Chi-Square test respectively. P2-4. Comparisons were made by the Mann-Whitney U test or the KruskalWallis test. $P$-values marked in bold are statistically significant $(P<0.05)$. P1. $P$-value obtained comparing inadequate medication literacy group versus adequate medication literacy in all groups. OR. odds ratio with a confidence interval $(\mathrm{Cl})$ of $95 \%$.

a. $\mathrm{OR}=0.592 ; 95 \% \mathrm{Cl}: 0.385-0.910 . P=0.019$ ( $P$-value obtained comparing male versus female)

${ }^{\mathrm{b}} \mathrm{OR}=0.312 ; 95 \% \mathrm{Cl}: 0.195-0.499 . P<0.001$ ( $P$-value obtained comparing $18-35$ years' group versus the rest of the groups

c. OR $=15.403 ; 95 \%$ Cl: 8.109-29.257. $P<0.001$ ( $P$-value obtained comparing primary level versus the rest of the groups)

d. $\mathrm{OR}=2.899 ; 95 \% \mathrm{Cl}: 1.887-4.453 . P<0.001$ ( $P$-value obtained comparing no medicines consumption versus the rest of the groups)

${ }^{\mathrm{e}} \mathrm{OR}=\mathbf{0 . 3 4 5} ; \mathbf{9 5 \%} \mathrm{Cl}: \mathbf{0 . 2 2 5}-\mathbf{0 . 5 3 0}, \boldsymbol{P}<0.001$ ( $P$-value obtained comparing consumption of chronic medication versus non consumption ${ }^{*} A l l$ values are expressed as mean \pm SD

significantly higher score for mean total medication and documentary literacy, and numeracy.

\section{Analysis of adequate or inadequate medication literacy} When sociodemographic characteristics and adequateor inadequate ML were analyzed (Table 1, Fig. 1), the results showed only 136 clients (34\%) had an adequate degree of ML, while the rest were seen to have inadequate ML $(n=264 ; 66 \%)$.
More men than women were adjudged to have and adequate level of ML (41.9 and $29.9 \%$, respectively; $P=$ 0.019 , OR $=0.592,95 \%$ CI: $0.385-0.910$ ). The analysis found statistically significant differences between the different age groups in terms of ML $(P<0.001$; OR $=0.312$; 95\% CI: $0.195-0.499)$, the $51-65$ and $>65$-year age groups having a lower frequency of adequate ML (23.5 and $7.1 \%$, respectively) than the rest of the age groups. A statistically significant increase in adequate ML was 


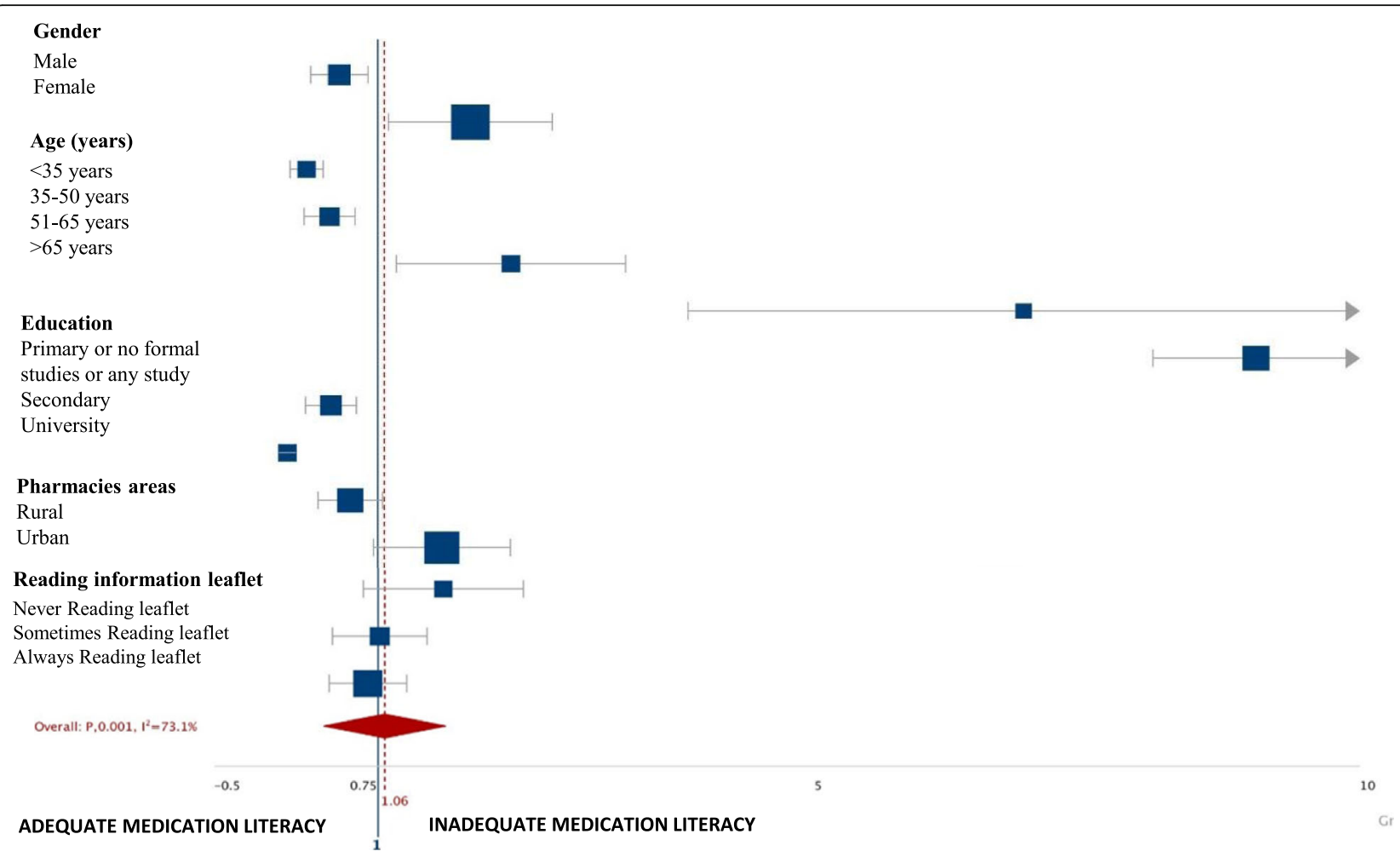

Fig. 1 Medication literacy comparing adequate or inadequate literacy in community pharmacy clients with different sociodemographic characteristics. The squares and horizontal lines correspond to the study-specific OR and 95\% Cl. The area of the squares reflects the weight (inverse of the variance). The diamond represents the OR and $95 \% \mathrm{Cl}$. Odds Ratios higher than 1 indicate the existence of a causal relationship between the sociodemographic variable analysed and inadequate medication literacy. The results are presented as Odds Ratio with a confidence interval (Cl) of 95\%. OR; Odds ratio;

LCL; Lower confidence level, UCL; Upper confidence level

observed as the academic level of the clients increased $(P<0.001 ;$ OR $=15.403 ; 95 \%$ CI: 8.109-29.257).

Similar results concerning adequate ML were found for the rural and urban pharmacies (39 and 30.5\% respectively, $P=0.086$ ). However, with regard to the number of medications, statistically significant differences are observed when comparing both study groups (adequateML and inadequate-ML; $P<0.001$; OR $=0.345 ; 95 \% \mathrm{CI}$ : $0.225-0.530$ ). A higher adequate literacy rate was observed for clients who did not take medicine (49\%) than for those taking some form of medication, 1-4 medicines $(31.8 \%$ and $\geq 5$ medicines $(7.1 \%) P<0.001$; OR $=$ 0.345; $95 \%$ CI: $0.225-0.530$ ). However, no significant statistical difference was found with respect to reading the information leaflets $(P=0.180)$.

Finally, analysis of the mean number of correct responses to the MedLitRxSE tool (14 questions) reflecting total medical literacy found an average of $10.30 \pm 3.41$ correct answers (mean points \pm SD; range: $0-14$ points) in the total population analyzed (Table 1). No difference was observed related with gender, both obtaining a similar and high percentage of correct answers $(P=0.075)$.

By contrast, a gradual decrease in the number of correct answers was observed when increasing age $(P<$
0.001). A gradual decrease in the number of correct answers was also observed as the number of medicines consumed increased $(P<0.001)$. A secondary school level of education was related with the highest number of correct answers $(12.67 \pm 1.46$, mean $\pm S D)$. No significant differences $(P=0.083)$ were associated with pharmacy location (rural or urban). Finally, a lower number of correct responses was observed in users that never read information leaflets compared with the clients who read always or sometimes the leaflet $(P=0.004)$.

\section{Analysis of documental literacy}

Analysis of the 10 questions that reflect the extent of documentary literacy in MedLitRxSEs showed an average number of correct answers of $7.06 \pm 2.51$ (mean \pm SD) in the total population analyzed (Table 1). Statistically significant differences were found between men and women $(P=0.008$; OR $=1.79 ; 95 \%$ CI $(1.17-2.73))$ as regards the number of correct responses but this association was not confirmed when multivariable analysis was applied ( $P=0.090$; OR $=1.54 ; 95 \%$ CI $(0.93-2.56)$; Table 2). The number of correct answers was lower in individuals over 65 years of age compared with the rest of ages analyzed $(P<0.001)$. On the other hand, a 
Table 2 Univariate and multivariate logistic regression of the MedLitRxSE, document and numerical literacy based on adequate ML

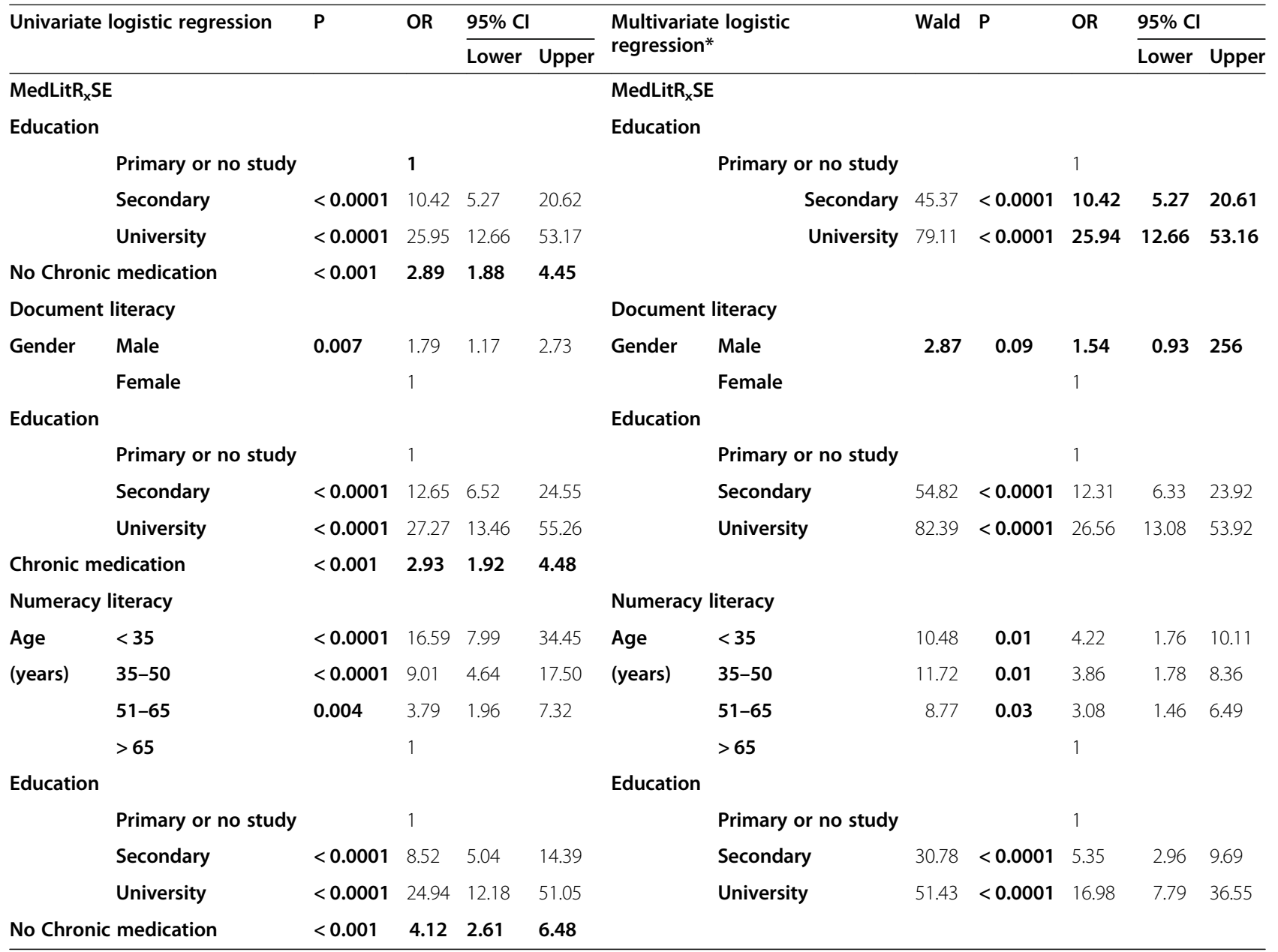

greater number of correct answers was observed in individuals with a minimum of secondary education $(8.79 \pm$ 1.28 , mean \pm SD) than in others groups. This association were confirmed when multivariable logistic regression analysis was applied $(P<0.0001, \mathrm{OR}=12.31 ; 95 \% \mathrm{CI}$ (6.33-23.92); Table 2). No association was observed between rural and urban area pharmacies $(P=0.069)$. Documentary literacy was higher in clients who did not take medicines compared with those that did $(P<0.001, \quad$ OR $=2.93 ; 95 \%$ CI (1.92-4.48). Patients with chronic medication use was also considered a factor associated with $\mathrm{ML}(P<0.001, \mathrm{OR}=2.93$; $95 \%$ CI (1.92-4.48), however this observation was not confirmed by multivariate analysis. However, best level of documentary literacy was recorded in pharmacy customers who always read the leaflets.

Finally, the different scenarios in the MedLiTRxSE tool for documental-ML were also analyzed (Fig. 2a). The greatest difficulty to answer adequately involved identifying the parts of the body to inject medicine (45\%, scenario \#3) and the daily doses per day of syrup medicines (54\%; scenario \#8). By contrast, there was a high frequency of correct answers (96\%) for identifying medicines that could only be prescribed by a doctor (scenario \#5) for identifying the name of a medicine (93\%; scenario \#9).

\section{Analysis of numerical literacy}

Analysis of the four questions that reflect the numerical literacy in MedLitRxSEs found a mean of $3.23 \pm 1.09$ (mean \pm DS) correctly answered questions by the total cohort (Table 1). As regards the sociodemographic characteristics analysed, numerical literacy did not differ with gender $(P=0.268)$ or the location of the community pharmacy $(P=0.154)$, but statistically significant differences were found as a function of age $(P<0.001)$, numerical literacy decreasing as the patient's age increased and also in terms of education level $(P<0.001)$. The patient's age was confirmed by multivariable logistic regression analysis $(P<0.0001$; Table 2$)$.

Individuals with primary studies or no formal studies showed a low level of numerical literacy $(1.86 \pm 1.17$; mean \pm DS) compared with individuals with a university 


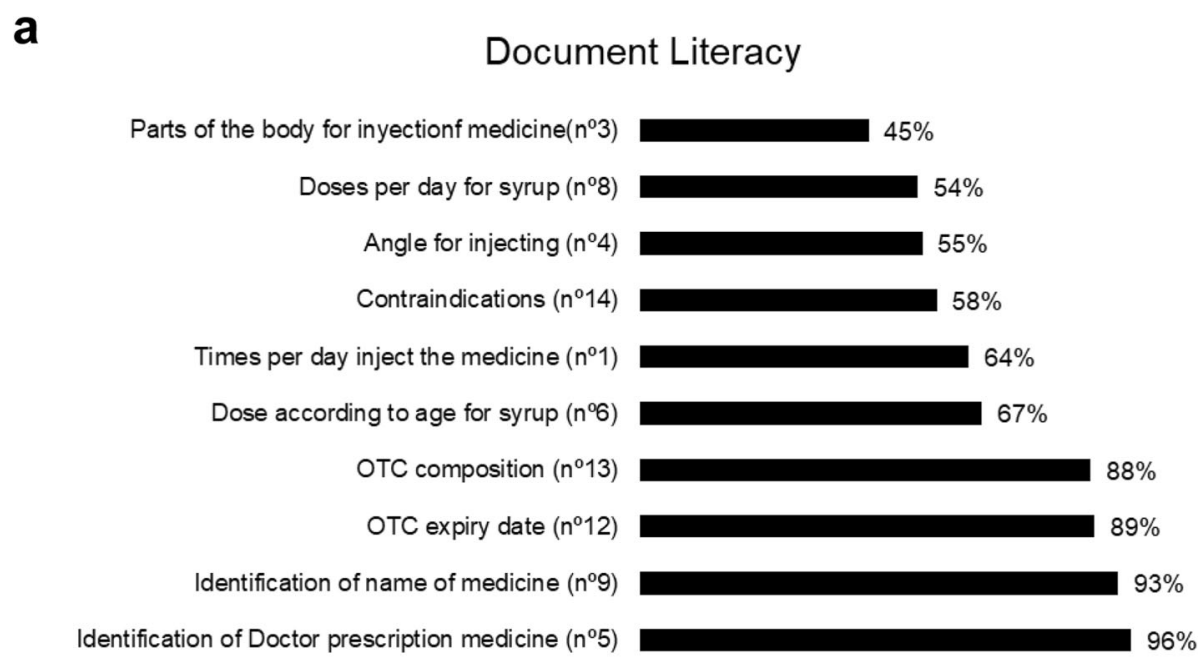

b

Numerical Literacy

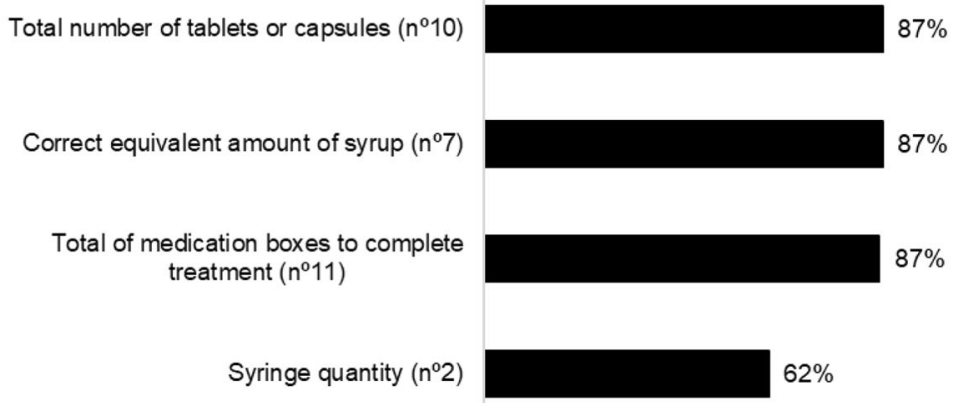

Fig. 2 Frequency of correct answers in the MedLiTRxSE tool. (a) Frequency of correct answers related to documental literacy (b) Frequency of correct answers related to numerical literacy

education $(3.88 \pm 0.35$; mean $\pm \mathrm{SD})$. These associations were confirmed through multivariable logistic regression analysis $(P<0.0001$; Table 2). Differences were also observed between individuals who never read the information leaflet and those who always read it $(P=0.002$; Table 1$)$.

When the frequency of correct answers in the MedLiTRxSE tool for numerical literacy were also analyzed (Fig. 2b), the numerical calculation of units of injectable medicine for diabetes (scenario \#2) was the problem that presented the lowest frequency of correct answers (62\%) compared with the rest of the questions whose frequency of success was $87 \%$ in all of them.

\section{Discussion}

In this study the ML of clients acquiring prescription and non-prescription medicines in community pharmacies was analyzed using MedlitRxSE questionnaire in order to know the medication literacy of users, with special emphasis on the chronically ill with the future purpose of designing new strategies that allow the pharmacist and health personnel to prevent and reduce the errors in taking medicines and thus avoid the undesirable effects of any misuse.

Pharmacists, as other health care providers, sometimes use terminology that their patients find difficult to understand. Moreover, in contrast to comprehensive (verbal) patient therapy, it is not unusual for health care providers, including pharmacists, to rely heavily on written patient education materials such as the leaflets that usually accompany medicines [20].

However, there are differences between what patients really understand and what health care providers, including pharmacists, expect or believe them to know. Patients with low reading ability have been found to be substantially less likely to understand and remember drug advice, and more likely to have trouble knowing exactly what most health professionals recommend [3, $19,20]$. 
The incorrect use of medication is a major problem, not only because it diminishes the effectiveness of medicines, but also because of the high frequency of problems associated with their misuse [25]. In this study, MedLitRxSE proved to be an effective and easy-to-use tool to assess the literacy of patients, and thus play an important role in ensuring patient safety and adherence to the instructions on how to use medicines provided by community pharmacies. Knowledge and improvement of ML could help reduce non-adherence to treatments, enabling patients to participate mor fully in their medication therapy [26].

Our result showed that only $34 \%$ of community pharmacy clients can be considered to have an adequate level of ML, which is similar to the findings of Sauceda et al. [13] in a population of 181 English and Spanish speaking patients in health centers and in the general population. Our results also suggest that ML decreases as the age of clients increase, as mentioned by Lee YM et al. [27]. Another study showed that patients with limited health literacy have a significantly low understanding of the instructions on the label of medicine containers, and therefore a higher risk of having problems related to the medication [28].

A predictive factor of adequate total, documental and numerical literacy was the educational level of participants. Moreover, in the case of numeracy, a younger age was also seen to be a predictive factor. The same factors associated with ML are also mentioned in the literature as predictors of health literacy $[29,30]$. In a study conducted by Osborn et al. [29] with 205 patients, health literacy was measured using the Rapid Estimate of Adult Literacy in Medicine (REALM) and the Wide Range Achievement Test, 3rd Edition (WRAT-3). The authors found that both numeracy and health literacy improved as the level of studies and income increased. Okamoto et al. [31] measured numeracy-ML in 300 people aged between 20 and 69 years using Lipkus and Schwartz scales. The first scale identified $46.33 \%$ of participants as having a low level of literacy, while the Schwartz scale identified $39.67 \%$ of participants as having a low literacy level. Men who had had a university education had the highest scores, while as age increased, the score decreased. Income did not have any effect on the results obtained for numeracy. In another study, using the short test on functional health literacy (S-TOFHLA) in a study of patients from different pharmacies in the United States, Backes and Kuo [32] observed that patients in general did not have an adequate functional level of health literacy, often did not remember the name of their treatment compared with patients considered to have a correct functional level of health literacy. The same occurred with remembering the correct dose and the frequency with which the medicine should be taken.
In view of our results, the advantages offered by using MedLitRxSE tool to analyze ML rather other health literacy questionnaires is that it allows the needs of clients, more specifically in the pharmaceutical environment, to be quickly and efficiently detected, thus improving pharmaceutical care and management of medications by the patient.

The results pointed to a decrease in adequate medication literacy as the number of medications consumed by the patient increases. However, in a study carried out by Lyles et al. [33] no association was found between health literacy and medication adherence or between health literacy and polypharmacy. Bauer et al. [34] studied the relationship between health literacy and adherence to following treatment correctly in a large cohort of patients treated with antidepressants during a 4 year follow-up and observed that $72 \%$ of patients could be classified as having limited health literacy, these patients show little adherence to medications compared to patients without such limitations.

Our results show that the scenario with the most problems of interpretation on the part of clients was that related with identifying the part of the body to inject a medicine. To solve this problem, it would be interesting to add illustrations to help patients with low levels of literacy to improve their understanding of how medicines should be used. Indeed, a study showed that this type of illustration could reduce errors both in the dosage of the medicine and resolve doubts about the part of the body where medication should be applied, at the same time increasing the degree of satisfaction with the care received in the community pharmacy in patients with low ML showed [35, 36]. However, another study carried out with that the use of illustrations did not reinforce the information received only in written form [37]. However, the illustrations must be clear because it has also been shown that the illustrations themselves may be a source of errors that result in improper administration of the medication [38]. One alternative to the use of written information and illustrations could be providing the information about medication in audio format. This has been used for treating patients with a low level of health literacy with statins, and was seen to increase knowledge about the medication and patient satisfaction compared with those who received the usual information materials [39].

In terms of numeracy-ML, $57 \%$ answered the 4 questions correctly, unlike in the study carried out by Osborn et al. [29], in which only $38.24 \%$ of participants were adjudged to have an adequate level of numeracy-ML. Participants in our study made mistakes most frequently in the question related with the medication dose required, which can lead to overdosing. It should be noted that users with medium level or higher education had a significantly higher level of total ML than users without 
formal education or those with only primary education. In a study conducted in 7278 community pharmacy patients throughout Spain, Romero-Sanchez et al. [40] observed that uneducated patients had a higher risk of not understanding the information on the medication than patients with primary, secondary or university level studies.

The more frequently patients read information leaflets, the higher their score for total, numeracy and document-ML. In this sense, some authors have suggested that the habit of frequent reading is a powerful tool for improving health literacy [41].

It should be noted that the MedlitRxSE questionnaire has not been used in a wide variety of situations. Although these cut-off points are due to expert criteria, a certain subjective charge cannot be denied as a limitation. To our knowledge, there are few instruments exclusively dedicated to measuring ML. Therefore, one of the problems with discussing the data is that it is difficult to compare our results with other studies specifically referring to ML, whether or not MedLitRxSE was used or other similar tools.

In addition, the survey used in our research to measure ML does not measure the communication skills of patients, which forms part of health literacy and is essential for interaction with health professionals, with the health care system and for understanding the warnings related to medication and health [42].

On the other hand, the original instrument was developed in the United States with a Spanish-speaking sample there. In our study, the instrument was used in a completely different context, being a limitation of our study. In the original developmental study, the instrument was validated showing that it was related to the Short Test of Functional Health Literacy in Adults (STOFHLA), a measure of health literacy with only a few questions that directly address medication management. Therefore, MedLitRxSE has been validated as a measure of general health literacy. It may have content validity due to the nature of the questions, however in our study we have taken into account that the measure of knowledge about drugs is only valid in the sense that it includes questions about medication management.

\section{Conclusions}

In conclusion, the MedlitRxSE questionnaire can be considered a useful tool for measuring ML effectively and rapidly in the community pharmacy. It is a structured, easy-to-complete tool for participants and useful for evaluating the knowledge, abilities and skills necessary for managing personal medication. Their use in the present study found that community pharmacy clients over the age of 51 and those with lower levels of education have a significantly lower LD level than younger age groups and those with higher levels of education. Knowledge of patient ML would help improve communication and contribute to increasing user knowledge and understanding of their illnesses and the pharmacotherapy involved. Such knowledge would increase adherence to treatment, and the clinical outcome and safety of the same. This should encourage pharmacists as health professionals to adopt strategies and initiatives that will improve the skills and abilities necessary for managing medication, especially in the population groups mentioned, for example, by encouraging patients to read information leaflets.

On the other hand, it should be noted that this analysis has allowed us to know the LA of the patients with different sociodemographic characteristics in the community pharmacies analyzed. Currently, pharmacists have access to the electronic prescription of all chronic patients who come to pick up their medication at the pharmacy. This study allows pharmacists to detect and know which group and which sociodemographic characteristics of their clients need more and more personalized attention, with more detailed explanations when drugs are dispensed, with the intention of reducing errors in taking medications.

\section{Supplementary Information}

The online version contains supplementary material available at https://doi. org/10.1186/s12877-020-01881-5.

Additional file 1: Table S1. Scenarios established in the MedLitRxSE tool for Spanish drugs, with their relevant questions and their relationship with literacy and documentary literacy.

\section{Abbreviations \\ Cl: Confidence intervals; I2: I-square; LCL: Lower confidence level; MedLitRxSE: Medication Literacy Assessment; ML: Medication literacy; OR: Odds ratios; REALM: Rapid Estimate of Adult Literacy in Medicine; SD: Standard deviation; S-TOFHLA: Short test on functional health literacy; UCL: Upper confidence level; WRAT-3: Wide Range Achievement Test, 3rd Edition}

\section{Acknowledgements}

We would like to thank the participants, who, by sharing their time and thoughts, have made this work possible.

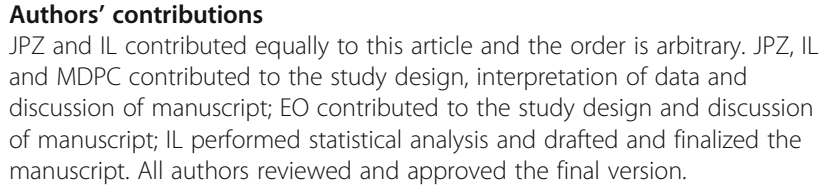

JPZ and IL contributed equally to this article and the order is arbitrary. JPZ, IL and MDPC contributed to the study design, interpretation of data and discussion of manuscript; EO contributed to the study design and discussion of manuscript; IL performed statistical analysis and drafted and finalized the manuscript. All authors reviewed and approved the final version.

\section{Funding}

This research did not receive any specific grant from funding agencies in the public, commercial, or not-for-profit sectors.

Availability of data and materials

The datasets used during the current study are available from the corresponding author on reasonable request. 


\section{Ethics approval and consent to participate}

All participants were informed of the study through the pharmaceutical staff attached to the community pharmacy obtaining written informed consent in all cases. The study and protocols for recruitment were approved by the Human Research Ethics Committee of the University of Murcia (Approval number: 1896/2018, date of approval 10 April 2019) in accordance with the 'Ethical Principles for Medical Research Involving Human Subjects' adopted in Declaration of Helsinki by the World Medical Association (64thth WMA General Assembly, Fortaleza, Brazil, October 2013).

\section{Consent for publication}

Not applicable.

\section{Competing interests}

The authors declare that they have no competing interests.

\section{Author details}

${ }^{1}$ Community Pharmacy, Health Service of Murcia, Murcia, Spain. ${ }^{2}$ Department of Legal and Forensic Medicine, Institute of Research into Aging. Biomedical Research Institute (IMIB), Regional Campus of International Excellence "Campus Mare Nostrum", Faculty of Medicine, University of Murcia, Murcia, Spain.

Received: 7 January 2020 Accepted: 9 November 2020

\section{Published online: 25 November 2020}

\section{References}

1. Advinha AM, De Oliveira-Martins S, Mateus V, Pajote SG, Lopes MJ Medication regimen complexity in institutionalized elderly people in an aging society. Int J Clin Pharm. 2014;36:750-6.

2. Monane M, Monane S, Semla T. Optimal medication use in elders. Key to successful aging. West J Med. 1997;167:233.

3. Doggrell SA. Adherence to medicines in the older-aged with chronic conditions: does intervention by an allied health professional help?. Drugs Aging. 2010;27:239-54

4. Hayes TL, Larimer N, Adami A, Kaye JA. Medication adherence in healthy elders. J Aging Health. 2009;21:567-80..

5. Zwikker HE, van den Bemt BJ, Vriezekolk JE, van den Ende $\mathrm{CH}$, van Dulmen S. Psychosocial predictors of non-adherence to chronic medication: systematic review of longitudinal studies. Patient Prefer Adherence. 2014;8: 519-63..

6. Baena MI, Faus MJ, Fajardo PC, Luque FM, Sierra F, Martinez-Olmos J, Cabrera A, Fernandez-Llimos F, Martinez-Martinez F, Jiménez J, Zarzuelo A. Medicine-related problems resulting in emergency department visits. Eur Clin Pharmacol. 2006;62:387-93.

7. McLachlan CYL, Yi M, Ling A, Jardine DL. Adverse drug events are a major cause of acute medical admission. Intern Med J. 2014;44:633-8.

8. Gazmararian JA, Kripalani S, Miller MJ, Echt KV, Ren J, Rask K. Factors associated with medication refill adherence in cardiovascular-related diseases: a focus on health literacy. J Gen Intern Med. 2006;21:1215-21.

9. Davis TC, Federman AD, Bass PF, Jackson RH, Middlebrooks M, Parker RM, Wolf MS. Improving patient understanding of prescription drug label instructions. J Gen Intern Med. 2009;24:57-62.

10. Hughes GF, McElnay JC, Hughes CM, McKenna P. Abuse/misuse of nonprescription drugs. Pharm World Sci. 1999;21:251-5.

11. Hoemme A, Barth $H$, Haschke $M$, Krähenbühl $S$, Strasser F, Lehner $C$, von Kameke A, Wälti T, Thürlimann B, Früh M, Driessen C, Joerger M. Prognostic impact of polypharmacy and drug interactions in patients with advanced cancer. Cancer Chemother Pharmacol. 2019:83:763-74.

12. Pazan F, Kather J, Wehling M. A systematic review and novel classification of listing tools to improve medication in older people. Eur J Clin Pharmacol. 2019;75:619-25

13. Sauceda JA, Loya AM, Sias JJ, Taylor T, Wiebe JS, Rivera JO. Medication literacy in Spanish and English: psychometric evaluation of a new assessment tool. J Am Pharm Assoc. 2012;52:e231-40.

14. Wolf MS, Davis TC, Shrank W, Rapp DN, Bass PF, Connor UM, Clayman M, Parker RM. To err is human: patient misinterpretations of prescription drug label instructions. Patient Educ Couns. 2007:67:293-300.

15. Zandieh SO, Goldmann DA, Keohane CA, Yoon C, Bates DW, Kaushal R. Risk factors in preventable adverse drug events in pediatric outpatients. J Pediatr. 2008;152:225-31.
16. Serper M, Patzer RE, Reese PP, Przytula K, Koval R, Ladner DP, Levitsky J Abecassis MM, Wolf MS. Medication misuse, nonadherence, and clinical outcomes among liver transplant recipients. Liver Transpl. 2015:21:22-8.

17. Braich PS, Almeida DR, Hollands S, Coleman MT. Effects of pictograms in educating 3 distinct low-literacy populations on the use of postoperative cataract medication. Can J Ophthalmol. 2011;46:276-81.

18. Raynor DK, Dickinson D. Key principles to guide development of consumer medicine information--content analysis of information design texts. Ann Pharmacother. 2009;43:700-6.

19. Elliott RA, Marriott JL. Standardised assessment of patients' capacity to manage medications: a systematic review of published instruments. BMC Geriatr. 2009:9:1-10.

20. King SR, MCCaffrey DJ, Bouldin AS. Alfabetismo en salud en el entorno de la farmacia: Definiendo el alfabetismo en farmacoterapia. Pharm Pract. 2011:9: 213-20

21. al Tehewy M, Fahim H, Gad NI, El Gafary M, Rahman SA. 2016. Medication administration errors in a university hospital. J Patient Saf 12:34-39.

22. Manfrin A, Tinelli M, Thomas T, Krska J. A cluster randomised control trial to evaluate the effectiveness and cost-effectiveness of the Italian medicines use review (I-MUR) for asthma patients. BMC Health Serv Res. 2017; 17:300.

23. Goerlich Gisbert F, Cantarino Ml. Estimaciones de la población rural y urbana a nivel municipal. Estadística Española. 2015;57:5-28.

24. Rucker DD, McShane BB, Preacher KJ. A researcher's guide to regression, discretization, and median splits of continuous variables. J Consum Psychol. 2015;25:666-78.

25. Soendergaard B, Kirkeby B, Dinsen C, Herborg H, Kjellberg J, Staehr P. Drugrelated problems in general practice: results from a development project in Denmark. Pharm World Sci. 2006:28:61-4.

26. Chang F-C, Chi H-Y, Huang L-J, Lee C-H, Yang J-L, Yeh M-K. Developing school-pharmacist partnerships to enhance correct medication use and pain medication literacy in Taiwan. J Am Pharm Assoc. 2015;55:595-602.

27. Lee Y-M, Yu HY, You M-A, Son Y-J. Impact of health literacy on medication adherence in older people with chronic diseases. Collegian. 2017;24:11-8.

28. Custodis F, Rohlehr F, Wachter A, Böhm M, Schulz M, Laufs U. Medication knowledge of patients hospitalized for heart failure at admission and after discharge. Patient Prefer Adherence Volume. 2016;10:2333-9.

29. Osborn CY, Wallston KA, Shpigel A, Cavanaugh K, Kripalani S, Rothman RL. Development and validation of the general health numeracy test (GHNT). Patient Educ Couns. 2013;91:350-6.

30. Paasche-Orlow MK, Parker RM, Gazmararian JA, Nielsen-Bohlman LT, Rudd RR The prevalence of limited health literacy. J Gen Intern Med. 2005;20:175-84.

31. Okamoto M, Kyutoku Y, Sawada M, Clowney L, Watanabe E, Dan I, Kawamoto K. Health numeracy in Japan: measures of basic numeracy account for framing bias in a highly numerate population. BMC Med Inform Decis Mak. 2012;12:104.

32. Backes AC, Kuo GM. The association between functional health literacy and patient-reported recall of medications at outpatient pharmacies. Res Soc Adm Pharm. 2012;8:349-54.

33. Lyles A, Culver N, Ivester J, Potter T. Effects of health literacy and polypharmacy on medication adherence. Consult Pharm. 2013;28:793-9.

34. Bauer AM, Schillinger D, Parker MM, Katon W, Adler N, Adams AS, Moffet $\mathrm{HH}$, Karter AJ. Health literacy and antidepressant medication adherence among adults with diabetes: the diabetes study of northern California (DIST ANCE). J Gen Intern Med. 2013;28:1181-7.

35. Condren ME, Desselle SP. The fate of pediatric prescriptions in community pharmacies. J Patient Saf. 2015;11:79-88.

36. Mohan A, Riley MB, Boyington D, Kripalani S. 2012. PictureRx: illustrated medication instructions for patients with limited health literacy. J Am Pharm Assoc. 2003;52:e122-9.

37. King SR, McCaffrey DJ, Bentley JP, Bouldin A, Hallam J, Wilkin NE. The influence of symbols on the short-term recall of pharmacy-generated prescription medication information in a low health literate sample. J Health Commun. 2012;17(Suppl 3):280-93.

38. Lokker N, Sanders L, Perrin EM, Kumar D, Finkle J, Franco V, Choi L, Johnston PE, Rothman RL. Parental misinterpretations of over-the-counter pediatric cough and cold medication labels. Pediatrics. 2009;123:1464-71.

39. Gossey JT, Whitney SN, Crouch MA, Jibaja-Weiss ML, Zhang H, Volk RJ. Promoting knowledge of statins in patients with low health literacy using an audio booklet. Patient Prefer Adherence. 2011;5:397-403. 
40. Romero-Sanchez J, Garcia-Cardenas V, Abaurre R, Martínez-Martínez F, Garcia-Delgado P. Prevalence and predictors of inadequate patient medication knowledge. J Eval Clin Pract. 2016;22:808-15.

41. Wister AV, Malloy-Weir LJ, Rootman I, Desjardins R. Lifelong educational practices and resources in enabling health literacy among older adults. $J$ Aging Health. 2010;22:827-54.

42. Pleasant A, McKinney J. Coming to consensus on health literacy measurement: an online discussion and consensus-gauging process. Nurs Outlook. 2011;59:95-106.e1.

\section{Publisher's Note}

Springer Nature remains neutral with regard to jurisdictional claims in published maps and institutional affiliations.

Ready to submit your research? Choose BMC and benefit from:

- fast, convenient online submission

- thorough peer review by experienced researchers in your field

- rapid publication on acceptance

- support for research data, including large and complex data types

- gold Open Access which fosters wider collaboration and increased citations

- maximum visibility for your research: over $100 \mathrm{M}$ website views per year

At BMC, research is always in progress.

Learn more biomedcentral.com/submissions 